
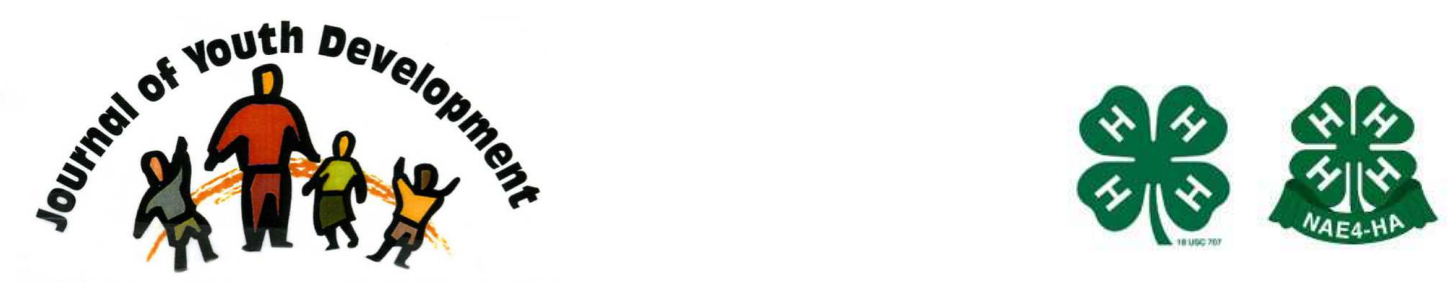

Bridging Research \& Practice

\title{
NikeGO: a Corporate-Sponsored Program to Increase Physical Activity and Foster Youth Development
}

\author{
Sarah Levin Martin \\ PEANUTC Evaluation Team \\ Centers for Disease Control and Prevention \\ Division of Nutrition and Physical Activity, \\ Atlanta GA USA \\ sjl2@cdc.gov \\ Maurice Martin \\ PEANUTC Evaluation Team \\ Molly White \\ Nike Incorporated, U.S. Community Affairs
}




\title{
JOURNAL OF YOUTH DEVELOPMENT \\ bridging research and practice

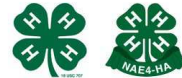

Bridging Research \& Practice

Volume 2, Number 1, Summer 2007

Article 0701PA002

\section{NikeGO: a Corporate-Sponsored Program \\ to Increase Physical Activity and Foster Youth Development}

\author{
Sarah Levin Martin and Maurice Martin \\ PEANUTC Evaluation Team \\ Molly White \\ Nike Incorporated, U.S. Community Affairs
}

\begin{abstract}
NikeGO was initiated in 2002 by the Nike US Community Affairs Division to address a growing need: to provide youth a safe environment in which to be physically active. Nike collaborated with several organizations across the country and offered an array of programs to foster developmentally appropriate physical activity among youth through their influencers (e.g., teachers, coaches). These programs reached youth in underserved areas ranging from urban inner cities to rural Native lands through various channels and settings including schools, Boys and Girls Clubs, YMCA's, youth sports organizations, and others. Objective and subjective measures were used to determine the reach of the program, the dose of physical activity, the "fun" level of the activities, changes in youths' self-esteem and self-concept, and the likelihood of continued participation. Many older youth gained leadership skills in the process. Overall, the programs have been successful in reaching "hard to reach" youth and engaging them in the positive, developmentally sensitive, health behaviors.
\end{abstract}




\section{Introduction}

NikeGO was established in 2002 by the US Community Affairs Division of Nike, Inc., communicating the simple mission: "Get kids moving and give them the means to do it." In its first two pilot years, NikeGO committed more than $\$ 20$ million in cash and products to fund programs aimed at encouraging children ages 9-15 years to be more physically active. NikeGO focused on the children's influencers (i.e., parents, teachers and coaches) who delivered the pilot programs, which were designed to give them the information and tools needed to enhance kids' chances of adopting long-term, physically active lifestyles.

Nike actively engaged in advocacy work at the state and national level, helping to build partnerships and information sharing that will lead to policy-level action to combat childhood obesity. Going forward, Nike will continue with its youth development programming, advocacy, and communication efforts to meet the health challenges faced by today's youth.

Regular physical activity offers an array of health enhancing effects (USDHHS, 1996) and provides a positive alternative to less healthy behaviors. Unfortunately, many factors in society are unwittingly reducing the opportunities youth have for regular physical activity. For example, some schools have reduced physical education offerings and recess in exchange for increased emphasis on academic test scores. Parents struggle to find time and safe space for physical activities; consequently many youth remain indoors and spend increasing amounts of time in front of a screen (TV, video games, computers).

Through youth development programming, NikeGO brings physical activity opportunities back to the nation's youth in underserved areas. The program is designed to offer thousands of children aged 9 - 15 years the motivation and means to discover the joy of movement and the fun of physical activity. Further, Nike is committed to program evaluation which helps the company not only measure the success of their programs, but also to make adjustment to continuously improve their youth development programming.

\section{NikeGO Programs}

The NikeGO youth development programs continue to evolve based upon societal needs and the results of professional program evaluations. Programs focus on four key initiatives:

(1) after- school and summer programs,

(2) NikeGO Places,

(3) PE2GO and in-school programs, and

(4) advocacy, and the related sponsorship of Shaping America's Youth (SAY; www.shapingamericasyouth.com).

Each initiative will be described below.

\section{After-School and Summer Programs}

NikeGO grants in 2003-04 and 2004-2005 were awarded to non-profit organizations and governmental partners, including: Boys \& Girls Clubs of America, Indian Health Service, Portland Parks and Recreation (in Oregon), Positive Coaching Alliance, Beyond the Bell among others. NikeGO also funded the evaluation of its programs to provide recommendations to Nike, its partners, and grantees for program improvement and to measure successes. 
Sports, Play, and Active Recreation for Kids (SPARK) has become an important partner with Nike in helping to design developmentally sensitive curricula and training for people who deliver active recreation programs to formerly at-risk youth.

\section{Boys and Girls Clubs}

Approximately 30 Boys \& Girls Clubs in major U.S. cities were funded each year since 2002 to conduct NikeGO programs that were created with the input of their members. The clubs' intent was to enhance their youth development program by engaging inactive youth in the NikeGO program, and to attract new youth to the program because of the new Nike involvement. To kickoff the program, Nike sponsored "SPARK Active Recreation" (out-of-school program) training for the clubs' staff. The SPARK philosophy aligns well with that of NikeGO; to include all youth, keep them active, and make the activity fun so the youth learn to enjoy movement. In addition to the staff training, each club was provided with funds to use at the club to support the youth development program (e.g. for adjunctive staff) and Nike equipment selected by each club according to its individual needs.

\section{On the TRAIL}

Staff at six Boys \& Girls Clubs from five Native American reservations, in partnership with Indian Health Services, were trained in "SPARK Active Recreation" as part of a larger diabetes prevention program called "On the T.R.A.I.L. (Together Raising Awareness for Indian Life) to Diabetes Prevention." These clubs used NikeGO grant monies to buy equipment and incentives for their youth development program.

\section{Portland Parks and Recreation}

Portland Parks and Recreation youth development program received funding to create afterschool opportunities for youth in Portland, Oregon in five school sites. Three elementary school sites used SPARK activities along with sports mixer sessions (i.e., varied activity offerings) while two middle schools and a high school conducted continuing instructional activities such as break-dancing, drill team, tae kwon do, soccer, and basketball. Portland Parks and Recreation also ran a summer youth development program since 2003 sponsored by NikeGO that featured fun physical activities to enhance existing less active activities.

\section{Positive Coaching Alliance}

The Positive Coaching Alliance (PCA) was funded by NikeGO to create a youth development workshops for African American and Hispanic communities within the Los Angeles area. PCA's mission is to "transform youth sports so sports can transform youth." The organization's goals are to

- replace the "win-at-all-cost" attitude with the "double-goal" of not only winning but, more importantly, using sports to teach life lessons,

- teach youth sports organization leaders how to create a culture where "honoring the game" is the norm, and

- spark and fuel a "social epidemic" of "positive coaching" across the country. PCA is using NikeGO funds to recruit and train bi-lingual, culturally appropriate trainers to reach out to Latino and African American coaches and parents in Los Angeles and New York City. 


\section{Beyond the Bell}

Beyond the Bell runs a NikeGO sponsored program called A World Fit for Kids (AWFFK). This after-school youth development program provides otherwise missing physical activity opportunities for youth in five middle schools in Los Angeles. The goal of AWFFK is to help students improve their own physical, mental, and emotional fitness through sports, fitness and peer leadership training.

\section{NikeGO Places}

Through this grant program, Nike installs, upgrades, and refurbishes play and sports courts and facilities throughout the U.S. using NikeGrind, a material created from recycled athletic footwear. As part of Nike's 30th anniversary in 2002, the company awarded Portland, Oregon, a $\$ 2.5$ million grant to refurbish 90 basketball courts in 35 metro-area parks. NikeGO will continue NikeGO Places as an integral component of its efforts to provide kids with safe, highquality places to be active.

\section{PE2GO}

PE2GO brings physical activity classes to fourth and fifth graders in public school who have had physical education classes reduced or eliminated due to scheduling issues or budget constraints. Nike views this initiative as a short-term solution to a much greater, long-term objective: to get physical education teachers back into those schools and insure that physical activity rounds out the education programming for students who otherwise might not have that the opportunity.

Nike partnered with SPARK to create developmentally appropriate curricula (PlaybookSPARK (R) and facilitation training support for classroom teachers in schools with reduced or no physical education. Nike also created and delivered custom equipment kits so that each student in a 36-child classroom had the equipment needed to be physically active for the full 30 minute class, without waiting for a turn.

\section{Shaping America's Youth (SAY)}

SAY is a national, cross-sector initiative devoted to youth development through the promotion of physical activity and healthy lifestyles among children. Nike, along with Gerber, Campbell Soup, Johnson \& Johnson and McNeil Nutritionals, sponsors SAY (www.shapingamericasyouth.com, 2004). In cooperation with private, public, and non-profit partners from across the country, SAY has created a registry and summary document describing funding, advocacy, and program efforts aimed at reversing the current childhood health crisis of sedentary lifestyles and poor eating habits for more than 2,000 programs in the non-profit, governmental and private sectors. The information gathered will enable and promote interactions, partnerships, and coordinated efforts among all concerned parties to improve the health of America's children.

\section{Evaluation Methodology and Selected Findings}

An independent program evaluate team evaluates each of the NikeGO youth development programs. The evaluation team provides a summary of its program-specific findings to Nike, its partners, and to the grant recipients for the purpose program improvement. The team uses a methodology termed, PEANUTC [Program Evaluation Across the Nation Using Technology(C) 
2004], to assess program processes of operation and effectiveness against two stated objectives:

1) to increase the time youth spend during the course of the program being physically active, and

2) to attract more kids to youth development programs by offering Nike sponsored physical activity programming.

The variety of program venues and array of activities offered by Nike contributions to youth programming required the use of a battery of evaluation strategies and techniques. For example, the evaluation of after-school programs includes paired-child interviews, direct observation of planned activities, and web-surveys of program administrators. The evaluation of the Native American reservation program includes a site visit, which included key informant interviews and observation. The PE2GO program evaluation includes focus groups and paperand-pencil surveys of teachers and web-based surveys of administrators. The PEANUTC process for the evaluation of the Nike contribution to the Boys \& Girls Club youth development programs is described in more detail elsewhere (Martin, 2004).

Findings from the first year of youth development programs that took place after school in 2002 - 2003 are archived on the internet (Harvard Out-Of School Database website, 2004). In the second and third year (2003-2005), the majority of Boys \& Girls Clubs youth development programs scored 4 or 5 on a 5-point scale, yielding examples of successfully run programs (i.e., increasing the time youth spend being physically active, and attracting more kids to youth development programs). The observations combined with the interviews with activity leaders revealed that "hard to reach" youth were reached through the unique activities offered.

The paired-child interviews revealed that many youth changed their self-concept since the program and now see themselves as an athlete, and view themselves as more active than prior to the program. In addition, some of the older youth in the Clubs (aged 15-18 years) have been trained to lead physical activity sessions for the younger children. Based on a case study approach, the evaluation found that this had a positive impact on teens as evidenced by marked boosts their self-esteem and self-confidence.

\section{Conclusion}

NikeGO provides a physical activity component to youth development programs and opportunities to thousands of youth in primarily underserved settings including urban inner cities and rural Native lands. The NikeGO initiatives are in line with evidence-based strategies to promote physical activity (Task Force on Community Preventive Services, 2002). Specifically, the programs in partnership with SPARK provide enhanced physical education (i.e., physical education that engages youth in moderate to vigorous physical activity and promotes lifelong physical activity); and the initiatives increase access to places to be active (e.g, in after-school settings and through the NikeGO Place, which refurbishes settings where physical activity can take place).

NikeGO programs work to increase the physical activity level of youth across a variety of settings through a variety of means. Many aspects of the program foster youth development, such as exposure to positive and fun behavior, team building skills, leadership experiences for the older youth, staff training for program infrastructure, and supportive relationships for the youth involved with adult leaders and peers. 
Each year, youth development organizations can apply for funding though the NikeGO website (www.nikego.com).

Corporate America is one of many players needed to help provide positive, health promoting behaviors as an alternative to less healthy behaviors often present in underserved areas. American companies have specific resources (communications, branding, capacity to drive demand and influence thinking, ability to create appropriate products and services, and financial resources) that can be used to help create and maintain youth development programs. Many corporations have begun the work through product creation and changes in communications efforts. When all business, government, and community sectors join together to leverage resources and talents, we may be able to create healthier lifestyles for American youth.

\section{References}

Harvard Family Research Project's Out-of-School-Time Program Evaluation Database. (2004). Available at: http://gseweb.harvard.edu/hfrp/projects/afterschool/evaldatabase.html Retrieved September 16, 2004.

Program Evaluation Across the Nation Using Technology. (Spring 2004). The Evaluation Exchange, Harvard Family Research Project, Cambridge MA.

Shaping American's Youth. (2004). Available at: http://www.shapingamericasyouth.com/sponsors.asp Retrieved August 23, 2004.

Task Forced on Community Preventive Services. (2002). Recommendations to Increase Physical Activity in Communities. Preventive Medicine, 22, 67-72.

United States Department of Health and Human Services [USDHHS]. (1996). Physical Activity and Health: A Report of the Surgeon General. (Atlanta GA: United States Department of Health and Human Services, Centers for Disease Control and Prevention, National Center for Chronic Disease and Prevention and Health Promotion).

(C) Copyright of Journal of Youth Development Bridging Research and Practice. Content may not be copied or emailed to multiple sites or posted to a listserv without copyright holder's express written permission. However, users may print, download or email articles for individual use. 